\title{
VALIDAÇÃO DE INFORMAÇÕES INTERCENSITÁRIAS (1991-2000) EM ESCALA INTRA-URBANA EM BELO HORIZONTE
}

Diego Rodrigues Macedo ${ }^{1}$

Glauco Umbelino ${ }^{2}$

\section{Resumo}

Este artigo trata das possibilidades de utilização de fotografias aéreas inseridas em Sistemas de Informação Geográficos (SIGs), com o objetivo elucidar a dinâmica intra-urbana nos setores censitários dos censos de 1991 e 2000, realizados pelo IBGE. O município de Belo Horizonte foi escolhido como área de estudo, por ter apresentado nesse período um constante adensamento domiciliar em sua área urbana e possuir fotografias aéreas de datas próximas aos dois últimos censos (1989 e 1999). Desta maneira, foram mapeados e selecionados os setores censitários marcados por um comportamento anômalo, ou seja, que apresentaram alto decréscimo de domicílios no período intercensitário, sugerindo um esvaziamento populacional em áreas nas quais se esperaria observar adensamento urbano. A partir dos dados de crescimento domiciliar e dos resultados da interpretação visual das fotografias nas duas datas, verificou-se que a Taxa de Crescimento Geométrico (TCG) negativa encontrada nestes setores anômalos não corresponde com a realidade exposta nos levantamentos aerofotogramétricos, que apresentaram um crescimento domiciliar positivo. Para validar as informações presentes no Censo 2000, foi realizada a comparação entre o número de endereços disponibilizados pela Prefeitura de Belo Horizonte em 2003 e os dados do IBGE em 2000, através de uma análise estatística de variância (ANOVA). Foi constatado que o número de domicílios apresentado no Censo 2000 está estatisticamente próximo ao número apresentado pela Prefeitura de Belo Horizonte, o que valida a boa qualidade das informações censitárias intra-urbanas do último censo. Tal fato vem elucidar a ocorrência de falhas na aquisição e/ou tabulação das informações censitárias de 1991 na escala intra-urbana.

Palavras-chave: setor censitário; fotografia aérea; SIG; geoprocessamento.

\footnotetext{
${ }^{1}$ Universidade Federal de Minas Gerais - Instituto de Geociências - Laboratório de Estudos Territoriais. Av. Antônio Carlos, 6.627 - 31270-901 - Belo Horizonte - MG (diegorm@ufmg.br)

${ }^{2}$ Fundação João Pinheiro - Centro de Pesquisas Aplicadas. Alameda das Acácias, 70 - 31275-971 - Belo Horizonte MG (glauco@fjp.mg.gov.br)
} 


\section{1- INTRODUÇÃO}

A informação advinda de sensores remotos, a bordo de aviões ou satélites, é uma importante ferramenta para o monitoramento de fenômenos dinâmicos e de mudanças produzidas nas áreas urbanizadas. O uso de fotografias aéreas em estudos urbanos se consolidou nos últimos 30 anos, em virtude de sua boa resolução espacial, tornando-se imprescindível para estudos relacionados à espacialização do meio urbano.

Atualmente é cada vez maior o número de estudos integrando as informações desta natureza com outros dados temáticos, apoiando-se, sobretudo em ferramentas de geoprocessamento. Em estudos intra-urbanos, observa-se a integração entre imagens espectrais, informações censitárias, além de níveis temáticos como arruamento, endereços, logradouros, dentre outros, como demonstrado em estudos recentes (ALVES, 2002; JAKOB \& CUNHA, 2005; UMBELINO \& MACEDO, 2006; UMBELINO, 2007).

O objetivo deste artigo é analisar a dinâmica intra-urbana em alguns pontos do município de Belo Horizonte entre 1991 e 2000. Neste contexto, foram escolhidos como unidade de análise alguns setores censitários que apresentaram evolução peculiar à esperada dentro deste município: um expressivo crescimento negativo do número de domićlíios.

Para auxiliar a compreensão desse processo da dinâmica urbana, as fotografias aéreas são de fundamental valia, pois são registros precisos da ocupação no determinado momento de sua aquisição. Este artigo utilizará um SIG para mesclar informações demográficas, tentando estabelecer diligências para se realizar uma pesquisa que pode validar as informações censitárias relativas à quantificação do número de domicílios na área de estudo.

\section{2- USO DOS SISTEMAS DE INFORMAÇÃO GEOGRÁFICOS (SIGS) EM ESTUDOS URBANOS}

Os Sistemas de Informação Geográficos (SIGs) procuram simular a realidade do espaço, permitindo o armazenamento, manipulação e análise de dados geográficos num ambiente computacional. Esses dados representam objetos e fenômenos em que a localização geográfica é uma característica inerente à informação e é indispensável para investigá-la (MONMONIER, 1997; DAVIS e FONSECA, 2001).

As principais características dos SIGs são (CÂMARA \& FREITAS, 1997): 
- Integração de informações espaciais provenientes de dados cartográficos, dados censitários e de cadastro urbano e rural, imagens de satélite, redes e modelos numéricos de terreno;

- Oferecimento de mecanismos para análise geográfica, através de facilidades para gerar, consultar, manipular, visualizar e plotar o conteúdo da base de dados geocodificados.

Uma das operacionalizações desses sistemas é o uso da informação advinda de sensores remotos (a bordo de aviões, balões ou satélites), revelando-se essenciais para o monitoramento de fenômenos dinâmicos e de mudanças produzidas no ambiente. O emprego dessas imagens em estudos urbanos está consolidado há décadas, principalmente em estudos geográficos, tendo como exemplo mais claro a confecção das cartas topográficas restituídas pelo Instituto Brasileiro de Geografia e Estatística (IBGE) e pela Diretoria de Serviço Geográfico (DSG), dentre outros órgãos.

Sua aplicação prática é extremamente útil em diversas nuances, como por exemplo, em uma administração municipal, sendo possível a elaboração de um banco de dados georeferenciado contendo todas as informações necessárias para o planejamento da cidade, incluindo: lotes, quadras, ruas, equipamentos urbanos (hospitais, escolas), redes de água, esgoto e luz, podendo ser consultado on-line pelas diversas secretarias municipais, por concessionárias de serviço e pelos cidadãos.

Os SIGs têm propiciado aos pesquisadores um ganho expressivo de informações, permitindo uma melhor compreensão da ocupação populacional em diversas áreas, com destaque às áreas urbanas. Em estudos de planejamento urbano, os SIGs tem diversas utilidades, desde trabalhos na escala nacional, até a escala intra-urbana, a começar pelo georeferenciamento de informações cadastrais de equipamentos públicos (educação e saúde) e de mortalidade, passando pela elaboração de surveys e índices, até a vetorização e consolidação da malha cartográfica digital dos setores censitários dos censos demográficos de 1991, 2000 e 2010.

Devido a essa ampla gama de opções, os profissionais que lidam com o planejamento têm adotado cada vez mais o SIG, sendo que, nos últimos encontros da ANPUR, trabalhos buscando integrar aspectos teóricos, metodológicos e práticos associados ao uso dos SIGs tem sido cada vez mais presentes (ANJOS \& OLIVEIRA, 2003; TRAVASSOS \& GROSTEIN, 2003). 
Objetivando a melhor elaboração das análises espaciais na escala intra-urbana, torna-se necessária a aquisição das informações em escalas espaciais menores que os municípios e distritos, como realizado neste artigo.

\section{3- FONTES DE DADOS DEMOGRÁFICOS NA ESCALA INTRA-URBANA}

No Brasil, as fontes de dados demográficos na escala intra-urbana são escassas. Com exceção do IBGE, nenhuma outra instituição produz dados nessa escala em abrangência nacional, confiabilidade e periodicidade. Em algumas localidades do país, principalmente nos grandes centros urbanos, existem instituições que produzem informações para atender a objetivos específicos, como a Fundação João Pinheiro (FJP), a Fundação SEADE, as Prefeituras Municipais e Secretarias Estaduais, dentre outros, cabendo ao pesquisador levantar quais são as fontes de dados disponíveis na sua área de estudo.

\section{1- Uso dos setores censitários de 1991 e 2000 como unidade de análise}

Inicialmente deve-se mencionar que os dados dos censos de 1991 e 2000 são disponíveis em várias escalas, sendo da maior para a menor: o País, as Grandes Regiões, os Estados, as Mesorregiões, as Microrregiões, as Regiões Metropolitanas, os Municípios, os Distritos, os Subdistritos, as Áreas de Ponderação e finalmente, a menor unidade territorial da base operacional do censo, que é o Setor Censitário (IBGE, 2002).

O Setor Censitário é definido como a unidade de coleta e controle cadastral, percorrida por um único recenseador, contínua e situada em área urbana ou rural de um mesmo distrito, em função do perímetro urbano (linha divisória dos espaços juridicamente distintos de um distrito, estabelecida por lei municipal). A área do setor deve respeitar os limites territoriais legalmente definidos e os estabelecidos pelo IBGE para fins estatísticos. Os limites do Setor Censitário foram definidos, preferencialmente, por pontos de referência estáveis e de fácil identificação no local (IBGE, 1991b).

$\mathrm{Na}$ coleta das informações dos censos de 1991 e 2000, foram usados dois modelos de questionário:

- Um questionário básico (documentação do universo) aplicado nas unidades não selecionadas para a amostra e contendo perguntas referentes às características básicas dos domićlíos e de seus moradores, que foram investigadas para $100 \%$ da população do Brasil;

- Um segundo questionário aplicado somente nos domicílios selecionados para a amostra, contendo, além das perguntas que também constam do questionário básico, outras perguntas 
mais detalhadas sobre características do domicílio e de seus moradores, referentes aos temas religião, cor ou raça, deficiência, migração, escolaridade, fecundidade, nupcialidade, trabalho e rendimento.

Somente os dados de setores censitários da documentação do universo podem ser utilizados nesta abordagem. Os dados dos setores censitários da amostra não podem ser usados devido à sua insignificância estatística, sendo que nesse caso a unidade mínima de análise á a Área de Ponderação, constituída por um agrupamento de setores censitários (IBGE, 2002).

Portanto, todos os dados utilizados neste trabalho são oriundos da documentação do universo, onde teoricamente, toda a população residente na data do recenseamento foi captada. Para este artigo, foi analisada a variável "número de domicílios" e de forma complementar, a variável "número de pessoas".

\section{2- Setores censitários de 1991}

Quando o IBGE fez o levantamento censitário de 1991, ainda não existia no Brasil a preocupação com a espacialização dos dados, que começou a ocorrer somente em meados da década de 1990. Este fato é confirmado pela indisponibilidade da malha que contém a delimitação dos setores censitários de 1991, em meio digital ou impresso.

Caso o pesquisador necessite dessas delimitações, pode-se adquirir junto ao IBGE uma planilha denominada "Descrição dos Setores", que contém o ponto inicial e o ponto final de cada polígono que constitui um setor. A título de exemplo, o setor censitário número 311.860.105.000.071.000 é chamado de "Entroncamento da Rua São Sebastião com a Avenida das Américas ou Avenida José Antônio da Rocha”. Sua descrição é a seguinte:

Do ponto inicial, segue pela "Avenida das Américas ou Avenida José Antonio da Rocha" até o "Ribeirão do Cabral", segue por este passando pela foz do "Córrego Feijão Mulato" até a foz de um "Afluente da Margem Direita" na qual se encontra uma "lagoinha" afluente da margem direita, segue até a "Rua Diamante", segue por esta até a "Rua Extrema", segue por esta até a "Rua Oscavo Lobata", segue por esta até a "Rua Angelina", segue por esta até a "Rua Extrema", segue por esta até a "Rua Lagoa Branca", segue por esta até a "Rua São Sebastião", segue por esta até o ponto inicial (IBGE, 1991b).

Como observado através dessa descrição, delimitar manualmente setor por setor é uma tarefa exaustiva, exigindo ainda a aquisição da base hidrográfica e de arruamento da área de estudo com a configuração de 1991, para que seja possível entender e traçar o que está escrito. 
No caso do município de Belo Horizonte, a Prefeitura Municipal, através do seu setor de mapeamento (Prodabel), já possuía os setores censitários de 1991 vetorizados e georeferenciados, gentilmente cedendo esta informação.

\section{3- Setores censitários de 2000}

No Censo de 2000, tendo em vista cobranças da sociedade e da comunidade acadêmica, o IBGE espacializou os dados demográficos na escala de setores censitários. O mapeamento do Censo 2000 foi construído utilizando-se tecnologia digital e teve como principais etapas de trabalho: a aquisição das bases cartográficas disponíveis, a atualização cartográfica; a representação da divisão político-administrativa, das divisões intra-urbanas e dos setores censitários; e a conversão para o padrão digital IBGE. Constitui-se, portanto, no primeiro acervo digital de cobertura nacional produzido pela instituição (IBGE, 2005).

Para municípios que em 1996 tinham população total acima de 25.000 habitantes, o IBGE passa então a disponibilizar em meio digital georreferenciado, as delimitações dos polígonos que formam os setores censitários, com um código de setor indexado para cada polígono.

\section{4- PROCEDIMENTOS METODOLÓGICOS}

\section{1- Compatibilização dos setores censitários de 1991 e 2000}

Inicialmente, deve-se ter em mente que para realizar qualquer análise temporal, a área dos setores censitários deve ser exatamente a mesma. De posse das bases de setores censitários de 1991 e 2000, foi necessária a compatibilização dos setores nas duas datas, conforme metodologia desenvolvida por Umbelino (2007).

Como o IBGE não manteve similaridades entre os códigos dos setores de $1991 \mathrm{com}$ os de 2000, optou-se por manter a nomenclatura do último censo, permitindo a comparação da mesma área territorial entre 1991 e 2000.

No caso específico deste artigo, foram selecionados apenas os setores censitários que apresentaram taxas negativas de crescimento populacional e do número de domicílios, e que apresentaram a mesma área nos dois censos demográficos, possibilitando uma análise direta de suas informações, e evitando possíveis problemas de agregação ou desagregação oriundos da base territorial. Deve-se também destacar que foram selecionados apenas os setores censitários que apresentaram decréscimo de pelo menos 100 domicílios entre 1991 e 2000, número que seria facilmente perceptível comparando as imagens aéreas do período analisado. Por último, foram 
selecionados apenas os setores censitários inseridos na parte setentrional do município, para simplificar a análise. A Figura 1 localiza estes setores em Belo Horizonte.
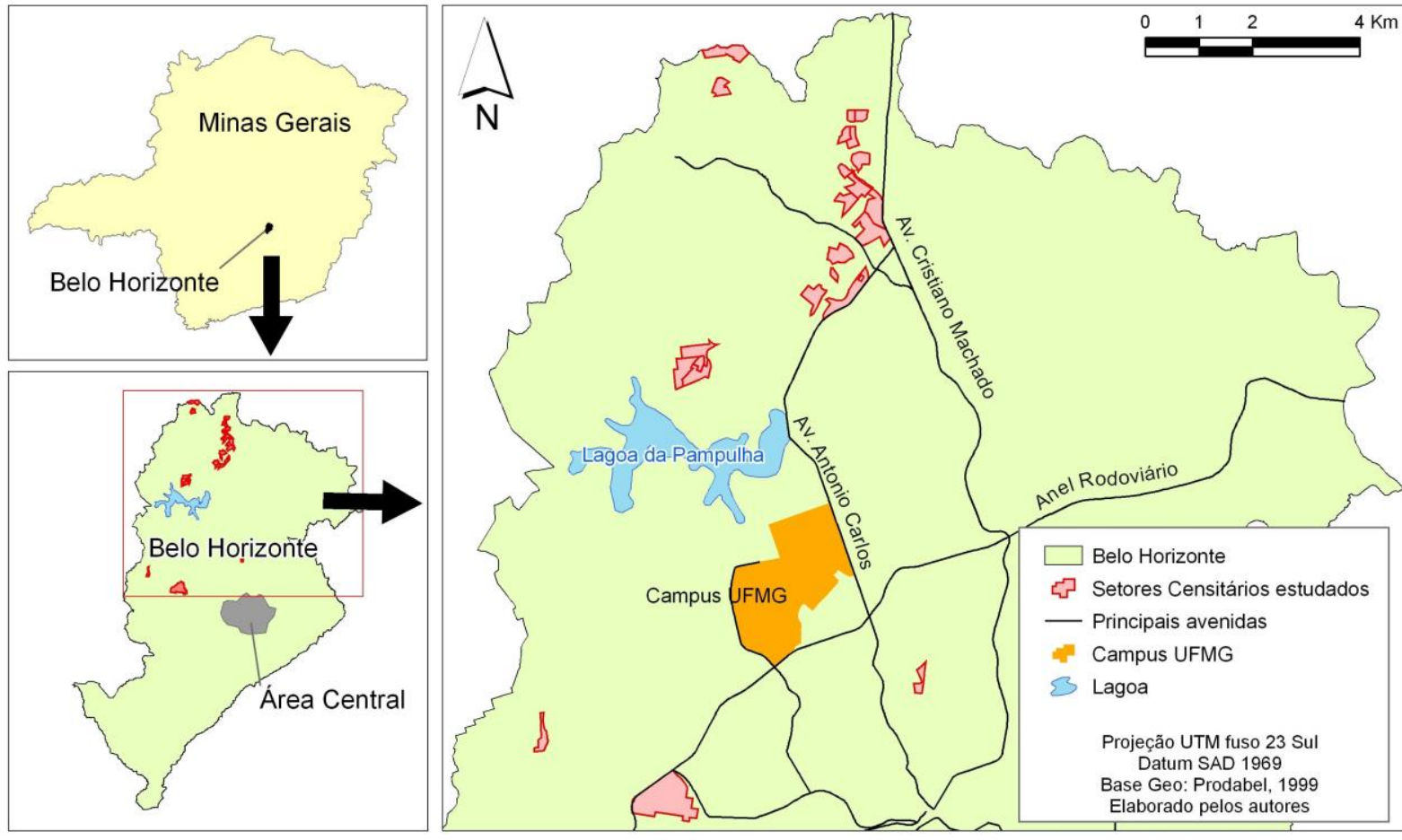

Figura 1 - Localização da área de estudo

Esta base de dados foi manuseada no pacote estatístico SPSS para os microdados de 1991, onde assim como nas bases cartográficas, criou-se uma nova coluna com os códigos dos Setores Censitários em 2000, utilizando-se o comando "Merge Files/Add Variables" que adiciona variáveis na base de dados a partir de um arquivo que possua uma coluna comum, no caso a coluna com o código do setor censitário em 1991, obtida no software MapInfo.

Para a manipulação dos dados de setores censitários em 2000, o procedimento é mais delicado, dado que o IBGE não disponibiliza os microdados do universo para 2000. Somente são oferecidos os resultados das tabulações, por setor censitário, no formato Excel. As planilhas do Excel foram convertidas para o formato SPSS e a partir daí, assim como para 1991, criou-se uma coluna com os códigos dos Setores Censitários em 2000, para que os dados pudessem ser 
trabalhados. A Tabela 1 apresenta os valores totais de população e domicilio para 1991 e 2000, assim como a Taxa de Crescimento Geométrico ${ }^{3}$ dos 27 setores censitários selecionados.

Tabela 1 - População total, número de domicílios e Taxa de Crescimento Geométrico (TCG) nos setores censitários analisados

\begin{tabular}{|c|c|c|c|c|c|c|c|}
\hline $\begin{array}{l}\text { Código do Setor } \\
\text { Censitário em } 2000\end{array}$ & $\begin{array}{c}\text { Pessoas } \\
\text { residentes } \\
\text { em 1991 }\end{array}$ & $\begin{array}{c}\text { Pessoas } \\
\text { residentes } \\
\text { em 2000 }\end{array}$ & $\begin{array}{c}\text { TCG } \\
\text { populacional } \\
1991-2000\end{array}$ & $\begin{array}{c}\text { Domicílios } \\
\text { em } 1991\end{array}$ & $\begin{array}{l}\text { Domicílios } \\
\text { em } 2000\end{array}$ & \begin{tabular}{c|} 
TCG \\
domiciliar \\
1991-2000 \\
\end{tabular} & \begin{tabular}{|c|} 
Domicílios a \\
menos em \\
2000 \\
\end{tabular} \\
\hline 310.620.005.640.037 & 938 & 537 & $-6,06$ & 269 & 161 & -108 & -108 \\
\hline 310.620 .005 .650 .053 & 1345 & 920 & $-4,17$ & 353 & 249 & -104 & -104 \\
\hline 310.620 .005 .650 .259 & 1201 & 714 & $-5,67$ & 336 & 192 & -144 & -144 \\
\hline 310.620 .060 .640 .110 & 2611 & 485 & $-17,20$ & 572 & 112 & -460 & -460 \\
\hline 310.620 .060 .690 .201 & 2031 & 1343 & $-4,53$ & 501 & 334 & -167 & -167 \\
\hline 310.620 .060 .690 .203 & 1962 & 1192 & $-5,44$ & 499 & 306 & -193 & -193 \\
\hline 310.620 .060 .690 .220 & 2070 & 1036 & $-7,47$ & 549 & 287 & -262 & -262 \\
\hline 310.620 .060 .690 .221 & 2448 & 1164 & $-8,00$ & 632 & 328 & -304 & -304 \\
\hline 310.620 .060 .690 .223 & 1814 & 1031 & $-6,14$ & 497 & 280 & -217 & -217 \\
\hline 310.620 .060 .690 .224 & 2138 & 797 & $-10,48$ & 545 & 223 & -322 & -322 \\
\hline 310.620 .060 .690 .227 & 2169 & 1096 & $-7,37$ & 506 & 281 & -225 & -225 \\
\hline 310.620 .060 .690 .228 & 2034 & 701 & $-11,26$ & 449 & 172 & -277 & -277 \\
\hline 310.620 .060 .690 .230 & 1407 & 294 & $-16,10$ & 324 & 63 & -261 & -261 \\
\hline 310.620 .060 .690 .231 & 2555 & 1465 & $-6,05$ & 580 & 387 & -193 & -193 \\
\hline 310.620 .060 .690 .233 & 1975 & 960 & $-7,77$ & 475 & 278 & -197 & -197 \\
\hline 310.620 .060 .690 .234 & 2157 & 1354 & $-5,09$ & 510 & 371 & -139 & -139 \\
\hline 310.620 .060 .690 .237 & 1906 & 1134 & $-5,66$ & 499 & 288 & -211 & -211 \\
\hline 310.620 .060 .690 .240 & 2250 & 990 & $-8,80$ & 523 & 255 & -268 & -268 \\
\hline 310.620 .060 .690 .242 & 2384 & 780 & $-11,78$ & 587 & 231 & -356 & -356 \\
\hline 310.620 .060 .690 .243 & 2396 & 662 & $-13,43$ & 561 & 181 & -380 & -380 \\
\hline 310.620 .060 .690 .244 & 1319 & 36 & $-33,23$ & 334 & 34 & -300 & -300 \\
\hline 310.620 .060 .690 .248 & 1718 & 1001 & $-5,88$ & 460 & 304 & -156 & -156 \\
\hline 310.620 .060 .690 .249 & 2557 & 1396 & $-6,56$ & 568 & 371 & -197 & -197 \\
\hline 310.620 .060 .690 .250 & 1865 & 503 & $-13,67$ & 461 & 163 & -298 & -298 \\
\hline 310.620 .060 .690 .251 & 2209 & 936 & $-9,18$ & 508 & 254 & -254 & -254 \\
\hline 310.620 .060 .690 .252 & 2756 & 1564 & $-6,16$ & 648 & 368 & -280 & -280 \\
\hline 311.860 .105 .000 .219 & 1035 & 571 & $-6,45$ & 252 & 150 & -102 & -102 \\
\hline
\end{tabular}

Fonte: IBGE, Censos Demográficos de 1991 e 2000.

\section{2- Fotografias aéreas}

Para a análise das mudanças ocorridas no período analisado, foram utilizadas fotografias aéreas do município de Belo Horizonte, obtidas nos anos de 1989 e 1999. A escolha destas ocorreu em função da disponibilidade de imagens nas datas mais próximas aos dois últimos

\footnotetext{
3 É a taxa de crescimento anual da população, dada pela expressão $T g=(P n / P o)^{1 / n}-1$ X 100, onde: Tg é a Taxa de Crescimento Geométrico; Pn é a população/domicílio ao final do período; Po é a população/domicílio no início do período e $n$ é o número de anos.
} 
levantamentos censitários. Para fins metodológicos, considerou-se que entre essas datas e data de referência dos censos, não ocorreram significativas alterações nos espaços analisados.

O levantamento aerofotogramétrico de 1989 está disponível apenas em meio impresso. Para realizar a análise via SIG, foi necessária a digitalização das pranchas por meio de um scanner de mesa formato A3. Posteriormente, efetuou-se o georeferenciamento no software ARCGIS 9.0, usando como pontos de controle um layer digital com os quarteirões de Belo Horizonte, observando sempre trechos onde não ocorreram mudanças entre as datas analisadas.

O procedimento efetuado com as fotografias de 1999 foi mais simples, pois a Prodabel possui em seu acervo esta informação digitalizada e georreferenciada, no software MapInfo. Para este estudo, foi apenas necessário à conversão do padrão MapInfo para o formato Geotiff, compatível com qualquer SIG.

Realizado este procedimento de georeferenciamento, as fotografias passam a ter uma perfeita sobreposição entre os dois níveis de informação (1989 e 1999). Como os setores censitários também estão georeferenciados, é possível analisar de forma integrada cada setor dentro da fotografia, nos dois períodos. A análise temporal foi realizada de maneira manual, observando atentamente as mudanças identificáveis na ocupação urbana da área de estudo.

\section{5- RESULTADOS}

Com base nas fotografias aéreas, cada setor censitário foi individualmente analisado. Nesta fase da pesquisa, houve uma importante constatação: todos os setores analisados apresentaram adensamento de domicílios, alguns facilmente perceptíveis na fotointerpretação. As figuras $2 \mathrm{a}, 2 \mathrm{~b}, 3 \mathrm{a}$ e $3 \mathrm{~b}$ exemplificam os resultados obtidos: 

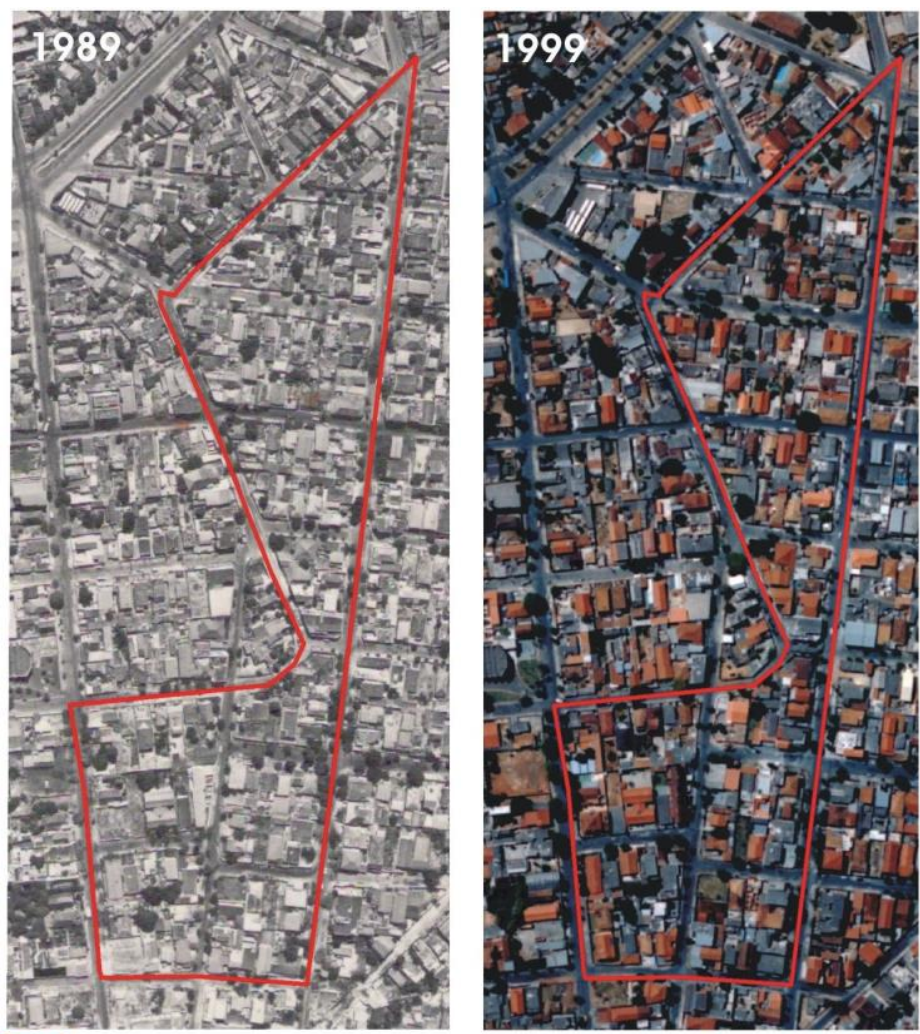

$\square$ Limite do setor censitário

Setor n.: 310.620.005.640.037

Domicílios 1991: 269

Domicílios 2000: 161

Figura 2a - Exemplo de setor censitário que apresentou baixo adensamento domiciliar
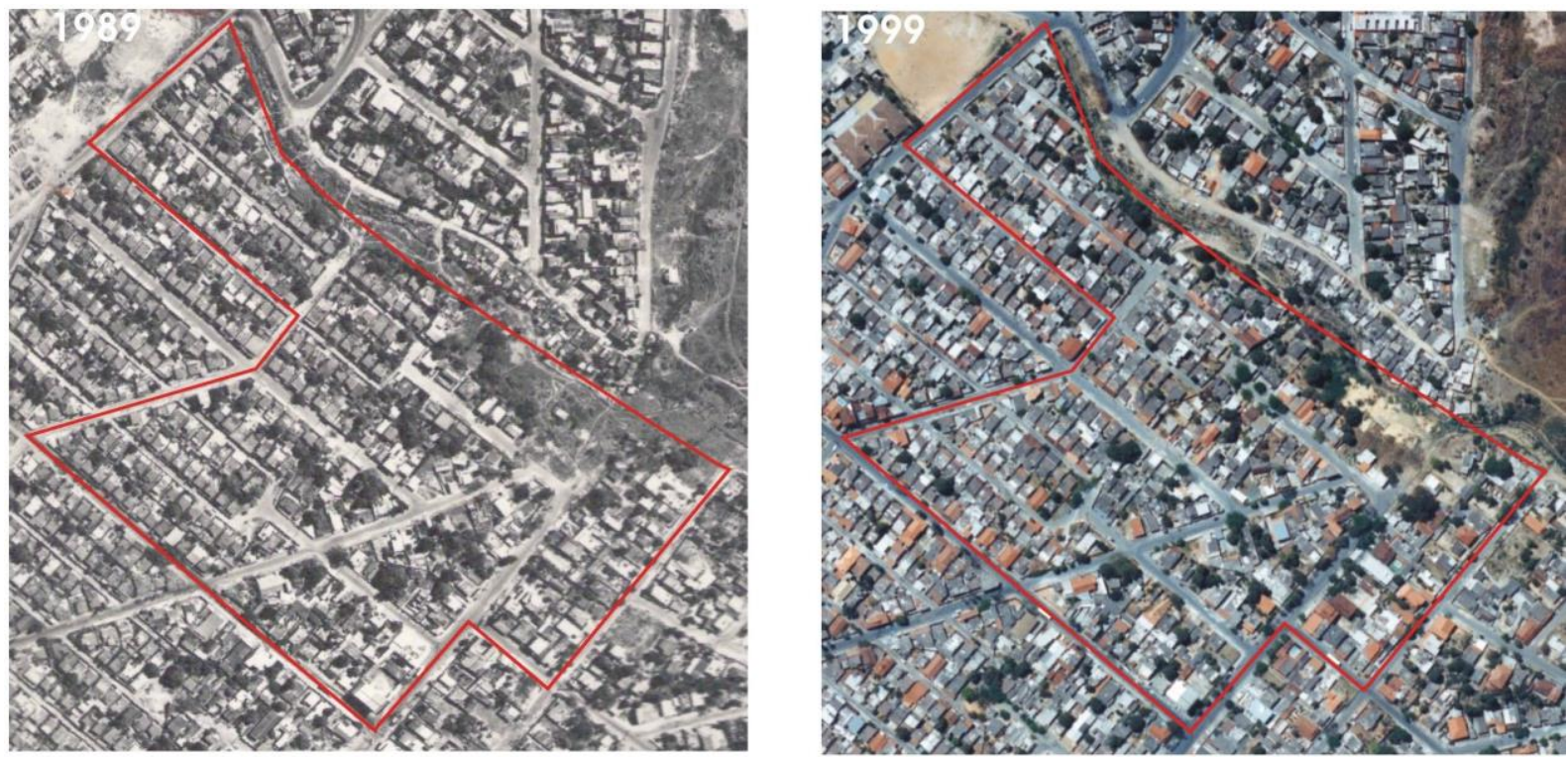

$\checkmark$ Limite do setor censitário

Setor n.: 310.620 .060 .690 .231

Domicílios 1991: 580

Domicílios 2000: 387

Figura 2b - Exemplo de setor censitário que apresentou baixo adensamento domiciliar 

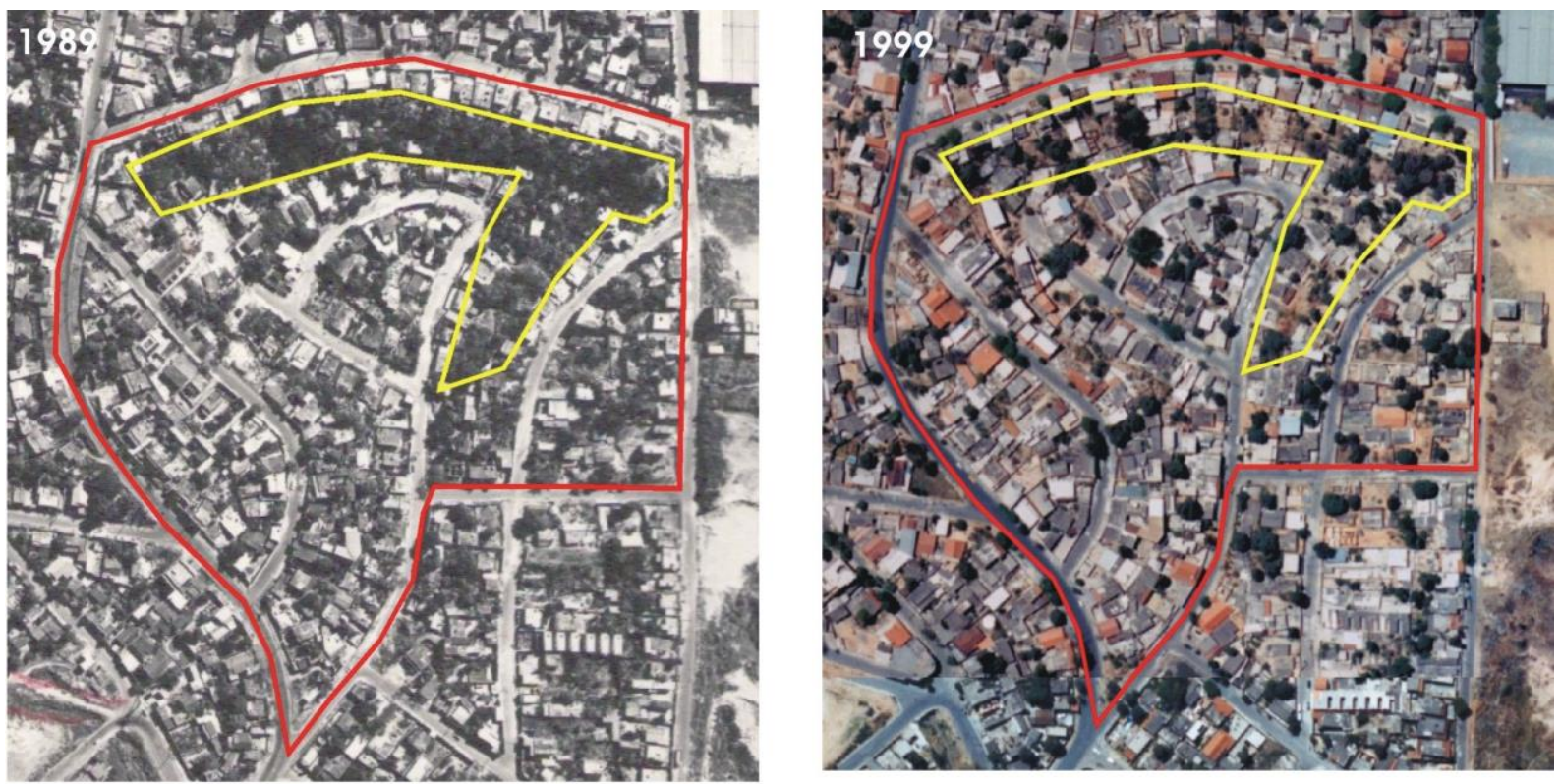

Limite do setor censitário

Áreas cuja o adensamento de domicílios é facilmente perceptível

Setor n.: 310.620.060.690.227

Domicílios 1991: 506

Domićilio 2000: 281

Figura 3a - Exemplo de setor censitário que apresentou alto adensamento de domicílios
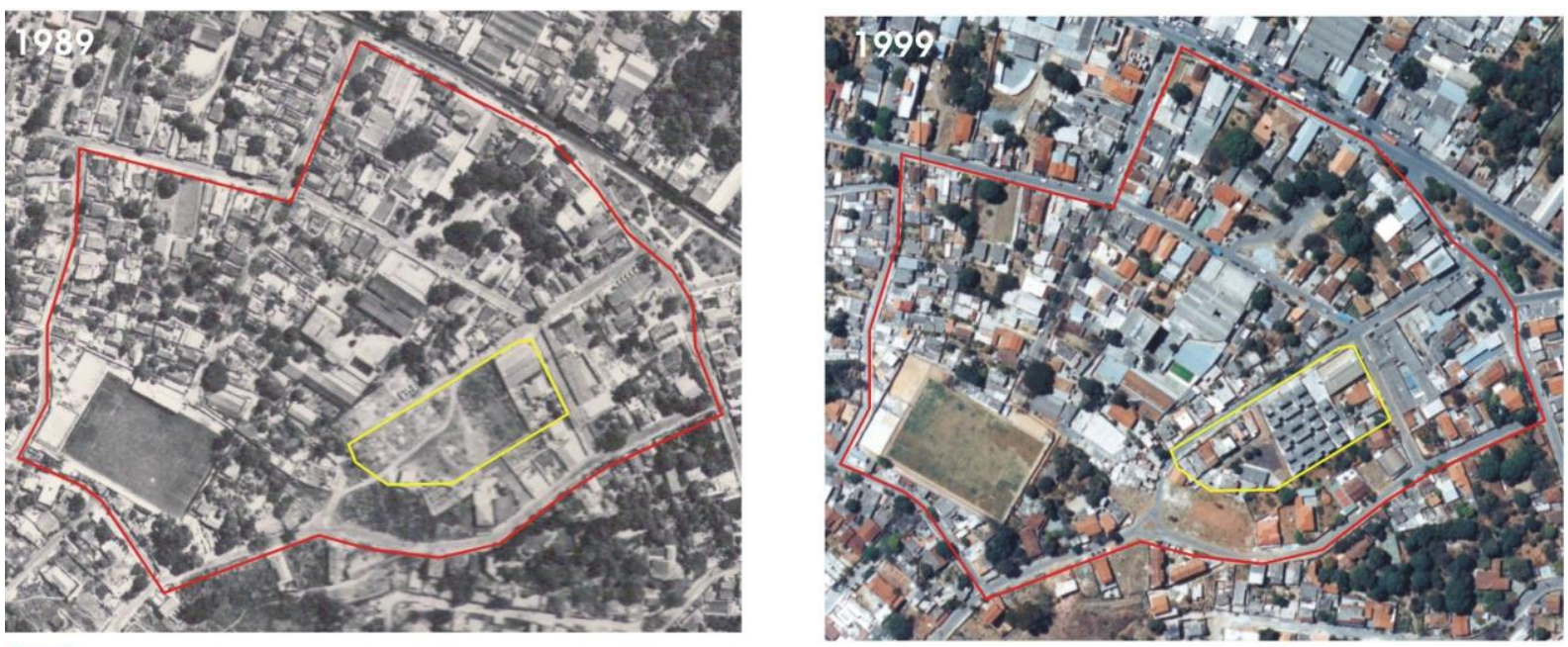

Limite do setor censitário

Áreas cuja o adensamento de domicílios é facilmente perceptível

Setor n.: 310.620.060.690.240

Domicílios 1991: 583

Domic'ilio 2000: 255

Figura 3b - Exemplo de setor censitário que apresentou alto adensamento de domicílios

As figuras acima demonstram o adensamento de domicílios, existindo basicamente duas situações: adensamento baixo, perceptível em alguns pontos em 12 setores censitários, e adensamento percebível em grandes áreas, em 15 setores censitários. Diante destes resultados, pode-se afirmar que existem problemas de aquisição e/ou tratamento dos dados entre 
recenseamentos, pois em nenhum dos setores observou-se o decréscimo de domicílios esperado, que em alguns casos seria de mais de 50\%. A Figura 4 apresenta a espacialização de cada setor censitário estudado com sua respectiva situação de adensamento.

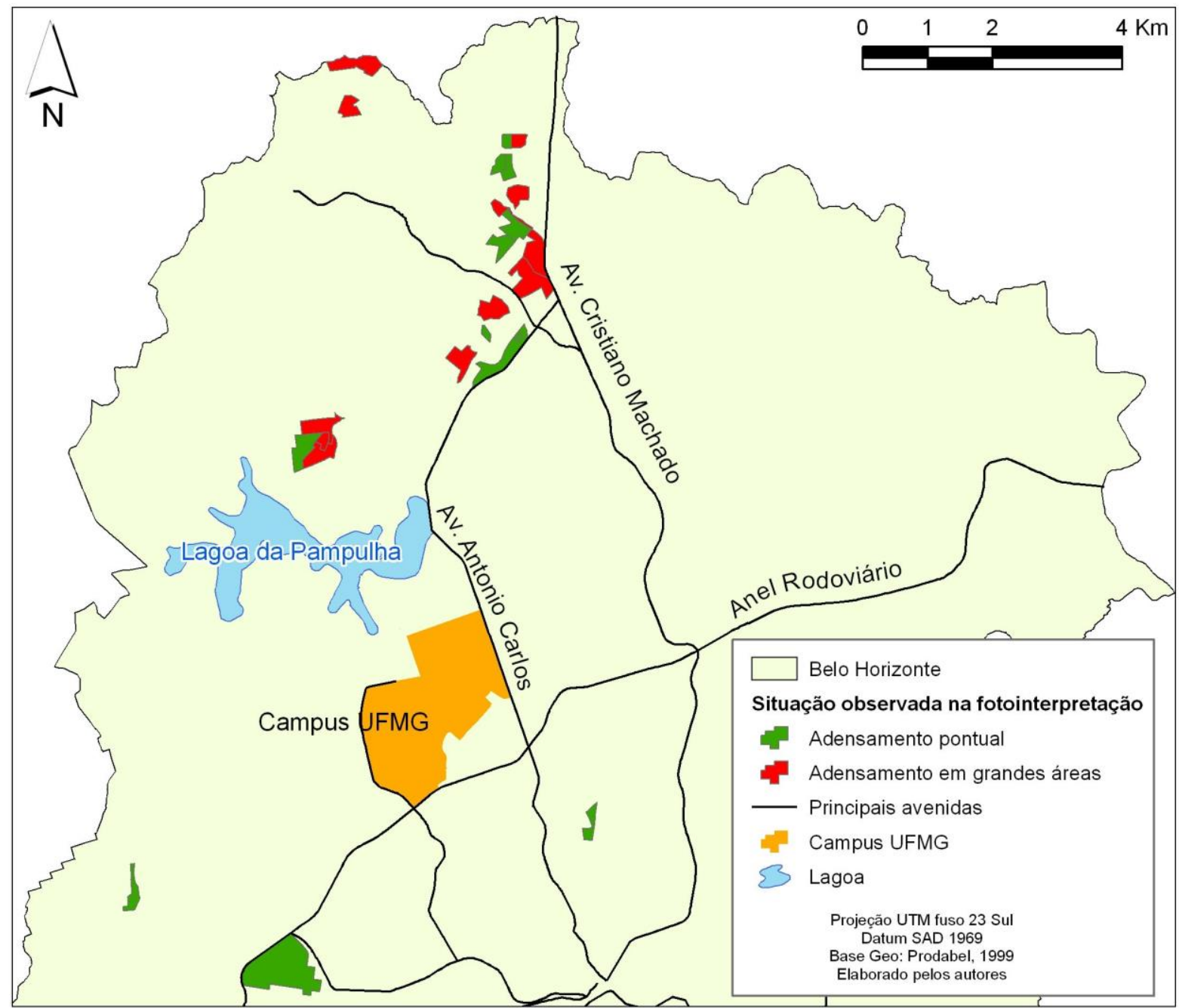

Figura 4 - Situação observada nos setores censitários

Observa-se na figura acima que não há uma clara correlação espacial entre a dinâmica de adensamento dos setores que apresentam falhas nos dados e sua localização no município.

Para averiguar em qual data há maior probabilidade de ocorrência de equívocos nos dados censitários, optou-se por comparar o número de domićlios apresentado pelo IBGE nos dois recenseamentos com o cadastro de endereços disponibilizado em ambiente SIG pela Prefeitura de Belo Horizonte, através da Empresa de Informática e Informação do Município de Belo Horizonte (Prodabel). Segundo Oliveira (2000), os endereços de Belo Horizonte foram cadastrados in loco pelos pesquisadores da Prodabel, que auxiliados por mapas na escala 1:1.000, identificavam o endereço no mapa, e posteriormente o cadastravam no banco de dados espacial. 
Este procedimento foi adotado em todo o município, com exceção dos aglomerados, que possuem um cadastro específico. A coleta maciça dos dados ocorreu entre 1996 e 1998, mas o cadastro se encontra em constante atualização anual. Desta forma, esta base contém mais de 90\% dos endereços municipais georeferenciados, e no caso deste artigo, foi utilizada uma versão repassada em 2003 ao Projeto Manuelzão/UFMG. Ressalta-se que os setores analisados estão localizados em áreas definidas como residenciais pela Lei de Parcelamento, Uso e Ocupação dos Solos de Belo Horizonte (Belo Horizonte, 1996), e desta maneira, acredita-se que o número de endereços cadastrados pela prefeitura seja bem próximo ao número real de domicílios.

Para constatar em qual levantamento censitário ocorreu o problema, foram formuladas duas hipóteses:

Hipótese (1): se o problema ocorreu nos dados do Censo de 1991, o número de domicílios deste censo deve ser maior que o número de endereços da Prodabel em 2003, ou;

Hipótese (2): se o problema ocorreu nos dados do Censo de 2000, o número de domicílios deste censo deve ser inferior ao número de endereços apresentados pela Prodabel em 2003.

Para testar as hipóteses, foram utilizados os dados apresentados na Tabela 2, que demonstra o numero de domicílios em 1991 e 2000 (IBGE) e o número de endereços da Prodabel em 2003. 
Tabela 2 - Número de domicílios (IBGE) e número de endereços (Prodabel) nos setores censitários analisados

\begin{tabular}{|c|c|c|c|}
\hline $\begin{array}{l}\text { Código do Setor } \\
\text { Censitário em } 2000\end{array}$ & $\begin{array}{c}\text { Domicílios } \\
\text { em } 1991 \text { - } \\
\text { IBGE }\end{array}$ & $\begin{array}{c}\text { Domicílios } \\
\text { em } 2000 \text { - } \\
\text { IBGE }\end{array}$ & $\begin{array}{l}\text { Endereços } \\
\text { em } 2003 \text { - } \\
\text { Prodabel }\end{array}$ \\
\hline 310.620.005.640.037 & 269 & 161 & 164 \\
\hline 310.620 .005 .650 .053 & 353 & 249 & 212 \\
\hline 310.620 .005 .650 .259 & 336 & 192 & 217 \\
\hline 310.620 .060 .640 .110 & 572 & 112 & 94 \\
\hline 310.620.060.690.201 & 501 & 334 & 298 \\
\hline 310.620.060.690.203 & 499 & 306 & 296 \\
\hline 310.620 .060 .690 .220 & 549 & 287 & 28 \\
\hline 310.620 .060 .690 .221 & 632 & 328 & 40 \\
\hline 310.620.060.690.223 & 497 & 280 & 76 \\
\hline 310.620 .060 .690 .224 & 545 & 223 & 24 \\
\hline 310.620 .060 .690 .227 & 506 & 281 & 164 \\
\hline 310.620 .060 .690 .228 & 449 & 172 & 179 \\
\hline 310.620 .060 .690 .230 & 324 & 63 & 62 \\
\hline 310.620 .060 .690 .231 & 580 & 387 & 277 \\
\hline 310.620 .060 .690 .233 & 475 & 278 & 217 \\
\hline 310.620 .060 .690 .234 & 510 & 371 & 251 \\
\hline 310.620.060.690.237 & 499 & 288 & 266 \\
\hline 310.620 .060 .690 .240 & 523 & 255 & 185 \\
\hline 310.620 .060 .690 .242 & 587 & 231 & 3 \\
\hline 310.620 .060 .690 .243 & 561 & 181 & 294 \\
\hline 310.620 .060 .690 .244 & 334 & 34 & 3 \\
\hline 310.620 .060 .690 .248 & 460 & 304 & 377 \\
\hline 310.620 .060 .690 .249 & 568 & 371 & 302 \\
\hline 310.620 .060 .690 .250 & 461 & 163 & 85 \\
\hline 310.620.060.690.251 & 508 & 254 & 279 \\
\hline 310.620 .060 .690 .252 & 648 & 368 & 356 \\
\hline 311.860 .105 .000 .219 & 252 & 150 & 0 \\
\hline
\end{tabular}

Uma análise superficial da Tabela 2 indica que o número de domicílios segundo o IBGE em 2000 está bem próximo aos dados da Prodabel, indicando que o problema ocorreu no Censo de 1991.

Para a confirmação dos resultados, foram utilizadas ferramentas estatísticas presentes no programa Statistica 7. Primeiro plotou-se um gráfico apresentando os três conjuntos de dados, representados na Figura 5. 


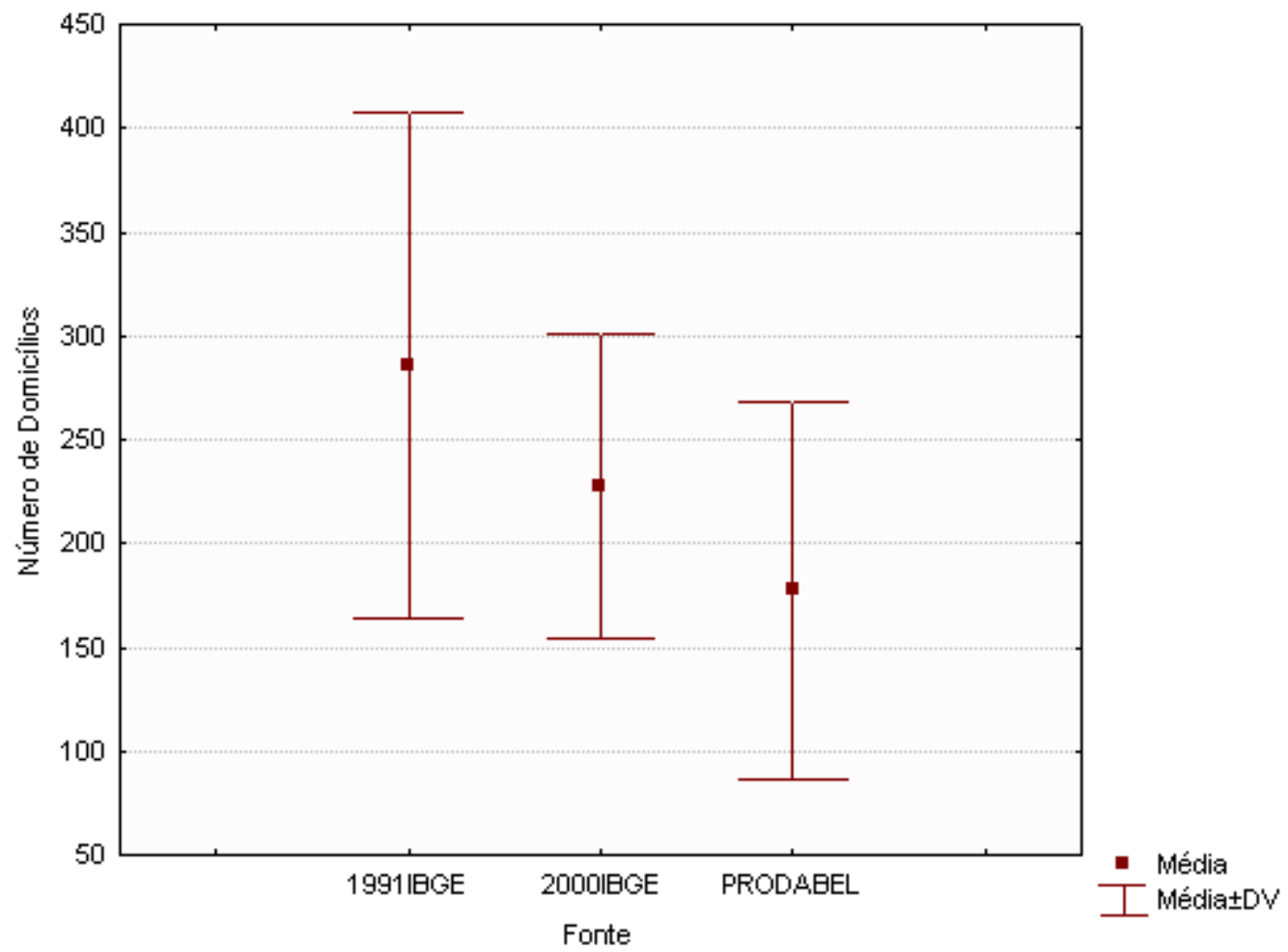

Figura 5 - Representação gráfica do número de domicílios entre as três fontes

O gráfico mostra claramente que os dados do IBGE em 1991 possuem mais domicílios que os dados do censo em 2000 e da Prodabel, contrariando os resultados empíricos da fotointerpretação, e indicando que a Hipótese (1) é coerente.

Finalmente, para validar as informações presentes no censo de 2000, foi utilizada uma análise de variância (ANOVA), que permite o particionamento da variação total em diferentes fontes e torna possível testar diferenças significativas entre médias de classes (StatSoft, 2001), ou em fontes de dados, como neste caso. Desta forma, foi aplicado o teste nos dados referentes ao Censo 2000 e à base da Prodabel em 2003, observando um valor de $p=0,13$. Considera-se que valores de $\mathrm{p}>0,05$ indicam que a hipótese testada é verdadeira (StatSoft, 2001), ou seja, os dois conjuntos de dados possuem alta similaridade.

Neste caso, pode-se afirmar que houve algum problema na aquisição ou na tabulação dos dados censitários de 1991, corroborando com os dados apresentados na Figura 5 e confirmando a Hipótese (1). 


\section{6- DISCUSSÃO}

Os resultados desse artigo podem ser utilizados no planejamento urbano e na formulação e implementação de políticas públicas, feitas pelas administrações municipais e entidades da sociedade civil, visando complementar as informações censitárias.

Este trabalho propõe avanços metodológicos ao relacionar dados censitários com fotografias aéreas, no sentido de confirmar se o recenseamento realmente reflete a situação real, tendo como base o número de domicílios. Como exposto na Tabela 1, a TCG populacional usualmente possui correlação direta com a TCG do número de domicílios, sugerindo que também há problemas nas variáveis referentes ao número de pessoas residentes nos setores censitários analisados em 1991.

Avanços metodológicos maiores foram prejudicados devido ao problema com a amostra de 1991. Este estudo não tem ferramentas para identificar em qual etapa do recenseamento ocorreu o erro, abrindo possibilidades para estudos futuros. Entretanto, acreditase que essa metodologia será útil, assim como aperfeiçoada, quando ocorrer à publicação do Censo de 2010. Vale ressaltar que várias prefeituras municipais vêm investindo na implantação e estruturação de SIG's, criando a expectativa de que, após o lançamento do censo de 2010, este tipo de validação possa ser aplicada em outros municípios. No caso específico de Belo Horizonte esta será uma realidade, pois a atualização dos endereços é constante.

As novas tecnologias de câmeras espectrais, com resoluções espaciais próximas à de levantamentos aerofotogramétricos (QUICKBIRD e IKONOS, principalmente), possibilitam a execução de estudos desta categoria em vários municípios brasileiros. Em um futuro próximo, esta facilidade será maior, graças à instalação de uma câmera de alta resolução (2,5 metros) no satélite Sino-brasileiro CBERS 2-B. A atual política do Instituto Nacional de Pesquisas Espaciais (INPE), órgão que opera o satélite, é de disponibilizar estas imagens gratuitamente, aumentando o acesso deste tipo de informação e facilitando a realização novas pesquisas.

Visando facilitar a pesquisa na escala dos setores censitários, o IBGE disponibilizou pela primeira vez os setores do Censo 2000 espacializados. Em contrapartida, trabalhar nessa escala ficou ainda mais difícil em relação à 1991, pois a instituição privou os pesquisadores de explorar os Microdados do Universo, fornecendo somente alguns resultados tabulados, o que prejudica o desenvolvimento de metodologias nessa unidade de análise, assim como trabalhos que necessitam de informações sobre os setores censitários. Portanto, na elaboração do Censo 2010, cabe ao IBGE refletir sobre uma maior democratização dos dados públicos, importantes para estudos 
que levam ao avanço científico, e à aquisição de informações para a implantação/avaliação de políticas públicas.

Outra questão fundamental que o IBGE deve refletir durante o planejamento do próximo censo, é sobre a delimitação dos setores censitários, que deve ser mais fidedigna possível às delimitações utilizadas no Censo 2000. Caso isso não seja realizado, setores da mesma localidade com delimitações diferentes entre 2000 e 2010, deverão ser compatibilizados, o que necessariamente aumenta a área analisada, prejudicando a realização de estudos temporais com um maior nível de detalhamento.

\section{REFERÊNCIAS BIBLIOGRÁFICAS}

ALVES, H. População e Desmatamento no Vale do Ribeira: integração de dados censitários com dados de sensoriamento remoto dentro da estrutura de um sistema de informação geográfica (GIS). In: Encontro da Associação Brasileira de Estudos Populacionais, 13, 2002. Ouro Preto. Anais Eletrônicos... Ouro Preto: ABEP, 2002.

ANJOS, M.; OLIVEIRA, J. Análise multitemporal da ocupação urbana na microbacia do Rio Sinhá localizada na região Norte da cidade de São José dos Campos - SP. In: Encontro Nacional da Associação Nacional de Pós-graduação e Pesquisa em Planejamento Urbano, 10, 2003. Belo Horizonte. Anais... Belo Horizonte: ANPUR, 2003.

BELO HORIZONTE. Lei no 7.166, de 27 de agosto de 1996. Estabelece normas e condições para parcelamento, ocupação e uso do solo urbano no Município. In: Diário Oficial do Município de Belo Horizonte, Belo Horizonte, 1996.

DAVIS, C., FONSECA, F. Introdução aos Sistemas de Informação Geográficos. Belo Horizonte: Departamento de Cartografia/UFMG, 2001.

MONMONIER, M. Cartographies of danger: mapping hazards in America. Chicago: University of Chicago Press, 1997.

CÂMARA, G, FREITAS, U. Perspectivas em Sistemas de Informação Geográfica. São José dos Campos: INPE, 1997. Disponível em: <http://www.dpi.inpe.br/gilberto /fatorgis95.pdf>. Acesso em: 27 set. 2006.

IBGE. Censo Demográfico de 1991 - Microdados do Universo. Rio de Janeiro: IBGE, 1991a.

IBGE. Descrição dos setores censitários do Censo Demográfico de 1991. Rio de Janeiro: IBGE, 1991b.

IBGE. Censo Demográfico de 2000 - Agregado por Setores Censitários dos Resultados do Universo. Rio de Janeiro: IBGE, 2002.

IBGE. Malha de setor censitário urbano digital do Distrito-Sede dos Municípios do Brasil em 2000. Instituto Brasileiro de Geografia e Estatística. Rio de Janeiro: IBGE, 2005. Disponível em: <ftp://geoftp.ibge.gov.br/mapas/malhas_digitais/setor_urbano/MG>. Acesso em: 12 jan. 2006. 
JAKOB, A.; CUNHA, J. Delimitação de áreas de segregação espacial da população na mancha urbana da Região Metropolitana de Campinas a partir de imagens de satélite e técnicas de estatística espacial In: SIMPÓSIO BRASILEIRO DE SENSORIAMENTO REMOTO, 12, 2005. Goiânia. Anais... Goiânia: INPE, 2005, p.3771-3778.

OLIVEIRA, C. M. Lançamento de Endereços no Geoprocessamento de Belo Horizonte. Disponível em <http://www.pbh.gov.br/prodabel/cde/publicacoes/2000/oliveira2000.pdf>. Acesso em 27 de Novembro de 2007.

STATSOFT, INC. STATISTICA (data analysis software system), version 7, 2001.

TRAVASSOS, L.; GROSTEIN, M. A ocupação de fundos de vale urbanos em São Paulo e sua dimensão sócio-ambiental. In: Encontro Nacional da Associação Nacional de Pós-graduação e Pesquisa em Planejamento Urbano, 10, 2003. Belo Horizonte. Anais... Belo Horizonte: ANPUR, 2003.

UMBELINO, G.; MACEDO D. Uso de Sistemas Informativos Geográficos (SIG's) na avaliação da dinâmica evolutiva de áreas urbanas: um estudo a partir dos Pólos Mineiros. In: Encontro da Associação Brasileira de Estudos Populacionais, 15, 2006. Caxambu. Anais Eletrônicos... Caxambu: ABEP, 2006.

UMBELINO, G. Proposta metodológica para avaliação da população residente em áreas de risco ambiental: o caso da bacia hidrográfica do Córrego do Onça/MG. 2006. 141 f. Dissertação (Mestrado em Demografia) - Universidade Federal de Minas Gerais, Centro de Desenvolvimento e Planejamento Regional, Belo Horizonte, 2007. 